Marketing in Asia Group

\title{
Emotional Intelligence and Organizational Citizenship Behaviour in Korea: The Mediating Effect of Social Networks
}

\author{
Hyewon Park \\ College of Business, Tennessee Technological University, TN, USA \\ Seung-Yoon Rhee \\ College of Business Administration, Hongik University, Seoul, Korea
}

\begin{abstract}
We examine the effect of emotional intelligence (EI) on help-giving and helpreceiving interactions in dyadic relationships. We further investigate how the dyadic reciprocity extends to organizational citizenship behaviour (OCB) toward whole group drawing on the collectivistic characteristics of East Asian culture. In addition, we use a social network approach to reveal how individuals' position in social networks mediates the relationship between EI and OCB. Through a two-wave survey study with $63 \mathrm{MBA}$ and graduate students, we found that emotionally intelligent individuals were more active in social networks. They showed more concentrated social interactions in acquaintance networks and engaged in more intermediary social interactions. Also, emotionally intelligent individuals received more assistance from various groups in the helping network. Furthermore, the more the emotionally intelligent individuals engage actively in social network, the more they engage in OCB later. Our study sheds light on the critical role that EI and interpersonal relationships play in understanding prosocial behaviour.
\end{abstract}

Keywords: Emotional Intelligence, Social Networks, Organizational Citizenship Behaviour, Prosocial Behaviour 


\section{Introduction}

Inquiry of why people exhibit prosocial behaviour or cooperate with others even when they could benefit more through selfishness has received extensive attention across diverse fields of research including psychology, sociology and behavioural economics (Simpson \& Willer, 2015). Extant research has suggested intra-psychic, interpersonal, organizational and macro-level antecedents of prosocial behaviour. For example, psychological research has emphasized individual factors such as personality and value orientation on cooperation (Thielmann et al., 2020) whereas sociological work has weighed on meso- or macro-level factors including culture, norms or rituals as sources of prosocial behaviour (Piliavin \& Charng, 1990). In behavioural economics, the rule of reciprocity is regarded as an important factor to predict cooperation (Simpson \& Willer, 2015). Despite the enduring interest in understanding the drivers of prosocial and cooperative behaviours, relatively little is known regarding how these drivers may work together to explain the phenomenon.

In this study, we explore how intra-psychic characteristics of individuals may relate to prosocial interaction in dyads, and how the dyadic interaction, in turn, leads to prosocial behaviour targeted at larger entities such as group or organization. More specifically, we examine the effect of individual emotional intelligence (EI) on helpgiving and help-receiving interactions in dyadic relationships. We further investigate how the dyadic reciprocity extends to organizational citizenship behaviour (OCB). We draw on the unique characteristics of East Asian culture and employ social network analysis method to empirically test the relationships.

EI refers to the ability to understand and regulate others' emotions as well as one's own by recognizing and controlling own and others' feelings (Mayer \& Salovey, 1997). Our focus on EI as an important antecedent of prosocial behaviour is based on the psychological findings of the role of emotion (i.e., empathy) in predicting prosocial behaviour (Thielmann et al., 2020). OCB, a type of prosocial behaviour, indicates actions that individuals voluntarily undertake, which allows the organization

to function more effectively. Indeed, a line of research pertains to the role of EI in predicting prosocial behaviour such as OCB (Carmeli \& Josman, 2006; Miao et al., 2017) and altruistic behaviour (Yusof et al., 2019).

There is a growing emphasis on EI as the majority of companies operate with teambased structure which necessitates collaboration and mutual understanding among team members. According to a recent trend report, about $62 \%$ of the firms worldwide opted for team-based structure (Bersin et al., 2016). The notion of EI is particularly important in Asian business context where maintenance of harmonious relationships and social bonds are important for effective functioning of teams and organizations. EI, by understanding and addressing others' emotions and feelings, can nurture highquality relationships that engender prosocial behaviour. OCB also plays a pivotal role in the Asian business context characterized by collectivistic culture. Organizations in this context tend to have a strong preference for employees equipped with EI who are willing to exhibit OCB through which social harmony and teamwork can be achieved. Hence, a deeper understanding of the notions of EI and OCB is warranted in the Asian business context in particular. 
Drawing on the ability-knowledge-motivation approach to citizenship behaviour as an overarching framework (Dudley \& Cortina, 2008), this research addresses three important questions. First, the underlying logic of the impact of EI on prosocial behaviour pertains to the ability of emotionally intelligent individuals to recognize, understand, and respond to co-workers' feelings and organizational needs (Carmeli \& Josman, 2006). According to the ability-knowledge-motivation framework, however, ability is one of the factors for effective prosocial behaviour, and that it further requires knowledge of co-workers' and organization's needs and goals and motivation to help others. The question of how one's social relationships foster knowledge and motivation needed for OCB has yet to be explored.

Second, our understanding is still limited in terms of what kinds of relational properties may foster motivation for OCB. In particular, relational properties tend to influence attitudes and behaviours differently across different cultures. In East Asia, horizontal and vertical relational properties tend to exert different effects on behavioural intention or motivation whereas there is relatively weak distinction in Western culture (Vignoles et al., 2016). In this study, we examine relational properties that foster prosocial motivation in East Asia. To identify different kinds of relational properties, we use social network analysis method which captures an entire social structure wherein a focal actor's behaviours occur (Scott, 2000). We analyze focal actor's quality of social relationships and the advantage they gain from these social ties by considering the entire social structure. This perspective enables us to empirically test the link between EI and help-giving and help-receiving relationships, which, in turn, leads to OCB.

Third, prior research on prosocial behaviour and cooperation within dyadic relationships has focused on explaining sources of prosocial motivation such as contagious pro-sociality (Nowak \& Roch, 2007) and good reputation as a reward (Besley \& Ghatak, 2018). However, researchers have rarely addressed the question of whether dyadic helping behaviour triggers prosocial behaviour toward the organization. We argue that, in the context of East Asia, dyadic prosocial behaviour is likely to be extended toward the organization more so than in the context of Western culture. Attributes of individualism and collectivism suggest that individuals in East Asian culture have propensity to perceive greater overlap between oneself and the organization and to attribute personal experience to the collective level (Arieli \& Sagiv, 2018; Triandis, 1995). Such cultural attributes of collectivism and interdependent selves in East Asia (Markus \& Kitayama, 1991; O’Neill et al., 2016) are likely to enhance the potential for dyadic pro-sociality to be extend to prosocial behaviour targeted at the organization.

In the following section, we adopt the ability-knowledge-motivation approach to citizenship behaviour (Dudley \& Cortina, 2008), and suggest that EI as one's ability to detect co-workers' feelings and needs fosters dyadic pro-sociality. We further propose that individuals in the help-giving and help-receiving dyadic relationships are likely to have opportunities to gain knowledge of co-workers' and organization's needs and goals. Those individuals, in turn, tends to be motivated to extend the target of prosocial behaviour and engage in OCB that benefits the organization. By using social network analysis method, we reveal relational structure of individuals as focal actors and identify their positions in help-giving and help-receiving dyadic relationships (i.e., central positions in acquaintance and helping network). We further 
examine how the prosocial dyadic relationships foster OCB, particularly in the East Asian context.

\section{Literature Review}

\section{Emotional Intelligence (EI)}

Emotion is, by its nature, essential to social interactions, because it conveys information about people's thoughts and intentions, and serves as a means of social communication (Keltner \& Haidt, 2001). Salovey and Mayer (1990) first introduced the term emotional intelligence, and conceptualized as including the following. Appraisal and expression of emotion is one's ability to show and to understand own and others' verbal and nonverbal emotion expressions. Regulation of emotion refers to one's ability to control own and others' emotions. Utilization of emotion is the ability to use emotion to enhance flexibility, creativity, and motivation by facilitating logical thinking process.

Later, Mayer and Salovey (1997) revised the EI model as having four components with an emphasis on the cognitive aspect. Perceiving emotion refers to the ability to recognize own and others' emotions through facial and verbal expressions. Using emotion refers to the ability to increase creativity and problem-solving skills through emotion. Understanding emotion encompasses the ability to understand emotional processes and the stimuli-emotion linkage. Managing emotion refers to the ability to change own or others' emotions for the benefit to oneself or others.

Wong and Law (2002) drew practical implications from Salovey and Mayer's theory by applying EI to work settings; self- and others' emotion appraisal (the ability to recognize and express own and others' emotion), use of emotion (the ability to use emotional information for constructive action and personal success), and regulation of emotion (the ability to regulate own and others' emotion to recover from psychological distress). Our conceptualization of EI is based on Salovey and Mayer's theory which includes appraisal, expression, regulation, and utilization of emotion.

Research on EI has gained momentum in the field of management. Prior research has revealed that, in addition to the positive effect of EI on quality social relationships, emotionally intelligent people were happier and more committed to their organization (Abraham, 2000) and exhibited successful performance (MacCann et al., 2020). Because emotions serve critical functions in social interaction such as conveying information about one's feelings and coordinating interactions, the ability to understand and manage emotions becomes crucial (Clarke \& Mahadi, 2017; Lopes et al., 2004). 
The ability of emotionally intelligent individuals matches the abilities and skills required for effective citizenship behaviour. The ability-knowledge-motivation approach to citizenship behaviour (Dudley \& Cortina, 2008) suggests that abilities including social perceptiveness, perspective-taking, and emotion perception and management skills facilitate effective citizenship behaviour. These abilities and skills overlap with the notion of 'contextual skill' (Motowidlo et al., 1997) needed to carry out effective handling of situations and helping others.

\section{Organizational Citizenship Behaviour (OCB)}

OCB refers to organizational members' discretionary behaviours taken voluntarily that benefit the organization. The actions of OCB are not formally recognized by the organization's reward system (Organ, 1988). OCB are behaviours that are neither official nor mandatory, but are beneficial to the organization's function and development. Examples of OCB include helping colleagues in need and putting more efforts on the job even when not required.

OCB is conceptualized with five dimensions. Altruism refers to task-related discretionary actions done to help colleagues or organization. Sportsmanship means persevering through hardships or withstanding inconvenient situations without complaining. Conscientiousness is going above and beyond the requirements of a given task. Courtesy is the idea of considering the consequences of one's actions before acting out to prevent conflicts. Finally, civic virtue involves active participation in decision-making out of concern for the organization, and acting responsibly.

Studies linking EI and OCB have argued that EI enables individuals to recognize, understand, and respond to others' emotions and needs (Carmeli \& Josman, 2006; Lopes et al., 2006a). In addition to the ability explanation, the ability-knowledgemotivation approach to citizenship behaviour (Dudley \& Cortina, 2008) suggests that, for OCB to be effective, knowledge of co-workers' and organization's needs and goals and motivation to help are necessary. This study addresses the question of how one's social relationships can foster knowledge and motivation needed for OCB.

We assume that individuals acquire the knowledge and motivation for effective OCB through their social relationships. Close relationships and frequent interactions with colleagues increase the likelihood of recognizing and understanding their needs and goals. Social bonds and attachment at workplace facilitate motivation to help colleagues (Dutton et al., 2010). Also, prior experience of receiving help from others can be an important driver for OCB (Grant et al., 2008).

Hence, we propose the structure and pattern of social relationships or interpersonal ties at workplace as the key mechanism underlying the link between EI and OCB. Social network analysis provides the view of the entire social structure wherein a focal actor's behaviours occur. We analyse the focal actor's quality of social relationships and the advantage they gain from these social ties (Scott, 2000). We 
propose a research model in which the focal actor's social networks mediate the relationship between his or her EI and OCB as conduit of knowledge of others' needs and motivation to help. Figure 1 depicts our conceptual model.

Figure 1: Research Model

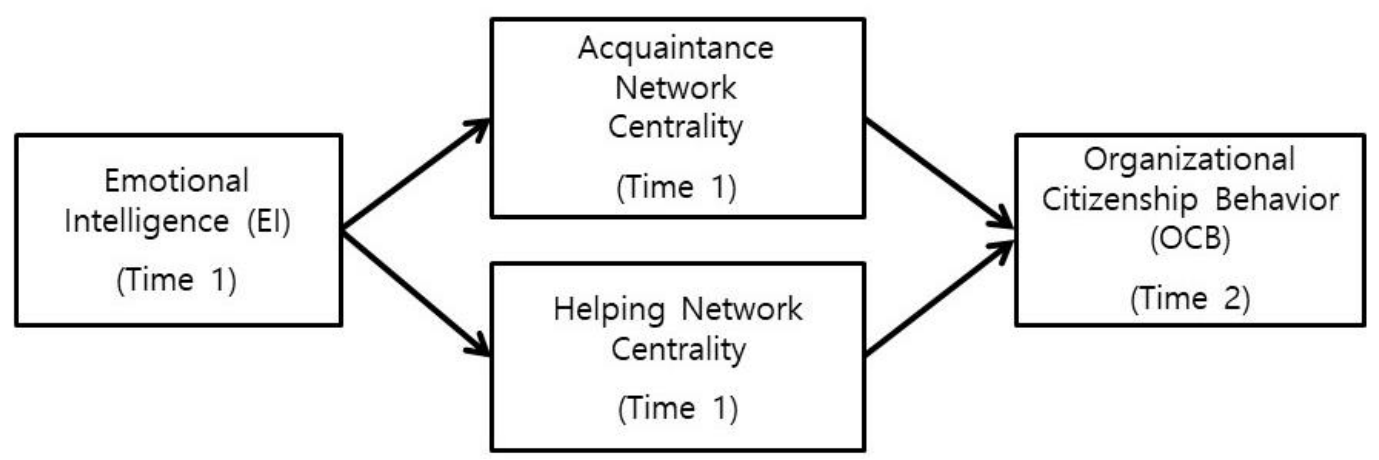

\section{EI and Social Networks}

Individuals with high EI accurately perceive and understand co-workers' emotional cues and respond to them properly. By doing so, they successfully build and maintain social relationships (Farh et al., 2012; Fang et al., 2015). Schutte and colleagues (2001) found that high EI individuals showed more empathic perspective taking, better social skills, and more self-monitoring in social situations. Also, higher scores on EI predict cooperative behaviours and affectionate relationships. Moreover, participants reported more satisfaction in their relationships with high EI partners than they did with low ones. These findings indicate that EI is associated with the quality of social relationships.

In this research, we apply the social network perspective to analyse the relationship between a focal actor's EI and social relationships. A social network is the pattern of social ties (Scott, 2000). Network structures based on actual social relationships provide accurate explanation for a focal actor's social constraints or advantages (Oh \& Kilduff, 2008). Social network analysis describes a focal actors' whole pattern of social interactions beyond simple dyadic interactions. Using social network analysis, we examine how EI influences the focal actor's pattern and structure of social relationships

We expect that high EI individuals would have more social relationships or ties, indicated by network centrality of acquaintance ties. The original idea of network centrality is to find the "star" or the centre person connected to the greatest number of people in the group. The concept of network centrality allows us to identify who the most popular person is in the group (Scott, 2000). The idea of network centrality of acquaintance ties means the extent to which a focal actor is preferred by other members within the acquaintance network. 
Here, we introduce two constructs of centrality (Scott, 2000). First, "in-degree centrality" captures how well-connected a focal actor is within the social network. It is measured as the number of the focal actor's incoming ties from other members within the network, which explains how popular the focal actor is in the social network. Next, "betweenness centrality" depicts the extent to which a focal actor connects the members of diverse groups within the network. High scores for betweenness centrality indicate that the focal actor serves as an intermediary or a broker among diverse groups.

In sum, individuals with high EI are preferred as working partners, primarily because they build and maintain relationships well through effective emotion management (Schutte et al., 2001). Thus, high EI individuals will receive more incoming social ties from colleagues and have more acquaintances within the network.

H1 The higher the EI score, the higher the individual will score on in-degree centrality in the acquaintance network.

EI predicts communication effectiveness and high-quality social relationships (Schutte et al., 2001), which enables those with high EI to build social capital (Lopes et al., 2006b) and influence others to get what they want (Lopes et al., 2006a). Thus, EI gets individuals to receive more social support they need from peers and leaders (Lopes et al., 2004). Another route pertains to one's ability to regulate emotion expression. Emotionally intelligent individuals tend to be skillful in expressing help needed through verbal and nonverbal cues (Lopes et al., 2006a), which increases the likelihood that they will receive the help needed. For these reasons, we anticipate that high EI individuals will receive more help from others and have more incoming ties in a helping network.

H2 The higher the EI score, the higher the individual will score on in-degree centrality in the helping network.

High EI individuals are better at regulating emotions to promote successful interactions with diverse groups. They actively seek emotional cues from members of diverse groups and attend to their needs (Lopes et al., 2004). Often times people have limited contact with members of other groups. In this situation, inappropriate emotional expressions are likely to evoke negative emotion in other groups due to a lack of prior interactions and mutual understanding (Lopes et al., 2004). The ability to regulate one's emotion and to respond properly to others' emotion becomes critical when interacting with unfamiliar group members with little interaction history. Hence, we expect that high EI individuals will be more socially adept across diverse social groups.

H3 The higher the EI score, the higher the individual will score on betweenness centrality in the acquaintance network. 
Close relationships with diverse groups enable individuals with high EI to cooperate with them better. Hence, individuals with high EI are likely to seek out more help from diverse groups, and are expected to receive more incoming ties from members of diverse groups.

H4 The higher the EI score, the higher the individual will score on betweenness centrality in the helping network.

\section{Social Networks and OCB}

Social exchange perspective (Konovsky \& Pugh, 1994; Mo \& Shi, 2017) has focused on reciprocal actions in dyads in explaining OCB. Relatively few studies took social network approach to show the effect of focal actor's relationship structure on OCB (Bowler \& Brass, 2006; Zagenczyk \& Powell, 2019). We draw on the abilityknowledge-motivation approach to citizenship behaviour to propose that individuals with multiple social relationships have more opportunities to gain knowledge of the needs and goals of co-workers and the organization. This approach postulates that contextual knowledge such as interpersonal construct knowledge, emotional knowledge, and organizational knowledge are imperative for effective citizenship behaviours (Dudley \& Cortina, 2008).

Interpersonal construct knowledge and knowledge of organizational norms and goals are key knowledge required for high quality OCB. Interpersonal construct knowledge refers to information about the interacting person's characteristics, attitudes and preferences. When a focal actor understands relationship properties well, he or she is more likely to comprehend the interacting person's needs and actually engage in helping behaviour (Dovidio et al., 2017). Organizational norm knowledge is information about the organization's ethics, traditions and culture. Understanding these rules and standards allows the individual to fully comprehend what the organization requires in each task and to collaborate and engage in helping (Böckler et al., 2016).

A social network tie is conceptualized as a conduit through which information, knowledge, support and resources flow in and out (Scott, 2000). Network centrality (i.e., occupying the central position in social network) implies having more incoming ties from other members in the network. Individuals high in network centrality can gather numerous information and knowledge, especially on their roles and responsibilities, co-workers' needs, and organizational norms and goals (Brass and Buckhardt, 1992).

In the context of East Asian culture, in particular, individuals occupying central positions in social network are often expected to perform duties and be responsible for others. Collectivistic culture emphasizes group cohesion even if it entails sacrificing one's self-interest (Arieli \& Sagiv, 2018). Furthermore, interdependent self-construal is characterized by subordinating personal goals to those of in-group (Markus \& Kitayama, 1991; Triandis, 1995). Such collectivistic tendency will be more evident for individuals occupying powerful, central positions because East Asians tend to notice high status individuals who are expected to be sensitive to their duties (Lin et al., 2013). Therefore, those who engage in social interactions with a larger number of 
people will be better at perceiving and addressing others' needs (Bowler \& Brass, 2006).

H5a The higher the in-degree centrality is in the acquaintance network, the more the individual will show OCB.

H5b The higher the betweenness centrality is in the acquaintance network, the more the individual will show OCB.

Moral behaviours such as OCB tend to be reciprocated and socially contagious (Rubenstein et al., 2019). Helping behaviours between co-workers are easily affected by reciprocity norm based on the belief that if one helps a co-worker, the co-worker will return the favour. Deckop and colleagues (2003) showed that favors individuals received from others motivated them to engage in helping behaviours.

The ability-knowledge-motivation approach to citizenship behaviour builds on the extant research to show motivation as a key predictor of OCB (Dudley \& Cortina, 2008). This is based on the volitional and discretionary characteristics of OCB, which assumes motivation of individuals to engage in the behaviour. If generalized reciprocity norms are established within teams or organizations, motivation to help and support others is expected to rise (Yoshikawa et al., 2018). Such generalized reciprocity norm tends to be pronounced in the collectivistic culture of East Asia (Triandis, 1995). Also, interdependent self-construal fosters collectivistic thinking by perceiving a large overlap between oneself and the group (Markus \& Kitayama, 1991; O'Neill et al., 2016). Hence, we hypothesize that individuals who receive more help from others are likely to exhibit OCB.

H6a The higher the in-degree centrality is in the helping network, the more the individual will show OCB.

H6b The higher the betweenness centrality is in the helping network, the more the individual will show OCB.

The overarching framework of ability-knowledge-motivation approach to citizenship behaviour (Dudley \& Cortina, 2008) suggests that the ability of emotionally intelligent individuals to understand and regulate own and co-workers' feelings and needs can generate dyadic prosocial behaviours such as help-giving and helpreceiving, in our case. In addition to being a central person in helping network, individuals with EI are capable of building and maintaining relationships, resulting in taking a central position in acquaintance network as well (Schutte et al., 2001). Accordingly, individuals with EI have more opportunities than others to gain knowledge of co-workers' and organizations' needs and goals. Having received help from others in the social network, the high EI individuals central in helping network, in particular, are likely to be motivated to reciprocate the favour by engaging in OCB. Hence, we hypothesize the mediating effect of social networks.

H7a The positive relationship between an individual's EI and OCB will be mediated by his or her acquaintance network in-degree centrality. 
H7b The positive relationship between an individual's EI and OCB will be mediated by his or her acquaintance network betweenness centrality.

H7c The positive relationship between an individual's EI and OCB will be mediated by his or her helping network in-degree centrality.

H7d The positive relationship between an individual's EI and OCB will be mediated by his or her helping network betweenness centrality.

\section{Research Method}

\section{Participants and Procedure}

We administered a survey to MBA and graduate students enrolled in an organizational behaviour class at a large business school in South Korea. The study was introduced as a part of class lecture on developing social networking skills. The survey was administered twice during a semester. A total of 104 students (50 MBA students and 54 graduate students) participated in either or both Time 1 and Time 2 (87 and 88 students participated in Time 1 and 2, respectively). Among the 104 responses, we used 63 responses (29 MBA students and 34 graduate students) in our analysis, excluding samples that participated only once. Among the 29 MBA students, 22 were male $(75.9 \%)$ and 7 were female $(24.1 \%)$. Among the 34 graduate students, 24 were male $(70.6 \%)$ and 10 were female $(29.4 \%)$. The gender composition of the sample roughly reflects that of Korean workforce employed in the top 100 South Korean companies (i.e., approximately male $80 \%$ and female 20\%) (The Outsourcing Times, 2019). All MBA students in our sample worked at the top 100 South Korean companies.

Time 1 survey was administered early in the semester and Time 2 survey about 1 month later. Time 1 survey assessed social networks (acquaintance and helping networks) and EI, and Time 2 survey assessed OCB. In our analysis, we used acquaintance and helping network centrality score measured at Time 1 so that there is an appropriate time lag between the mediating variables and the outcome (i.e., OCB). Time 1 survey was administered after about a month had passed since the beginning of the semester. We believe that 1-month period was sufficient for social relationships to form in the class through orientation activities, small group discussion, and team project preparation. Therefore, it is deemed appropriate to analyse the relationship between EI, which is a relatively stable characteristic, and social network positions at Time 1. 


\section{Measures}

EI was measured using Self-Rated Emotional Intelligence Scale (Brackett et al., 2006). The 19-item measure assesses five components: perceiving emotion, use of emotion, understanding emotion, managing emotion, and social management. Sample items include "When making decisions, I listen to my feelings to see if the decision feels right" and "By looking at people's facial expressions, I recognize the emotions they are experiencing". Participants responded on a 5-point Likert-type scale. We aggregated the five components and used as a single variable $(\alpha=0.824)$.

Social networks were measured in two ways. Acquaintance networks were assessed by asking how well the participants knew each of the students in the class. We used a 4-point scale: $0=$ do not know, $3=$ know very well. Helping networks were measured by asking if the participants gave help to each of the students in the class. They responded either 1 (yes) or 0 (no). We used UCINET 6 to obtain in-degree centrality and betweenness centrality scores. In-degree centrality is measured by the number of ties focal actor receives from the other members of the network (Borgatti et al., 2002). Betweenness centrality represents the frequency with which an actor falls between other pairs of actors on the shortest (i.e., geodesic) paths connecting them (Oh \& Kilduff, 2008).

OCB was assessed using a modified 11-item scale by Podsakoff et al. (1997) on a 5point Likert-type scale. Sample items include "I keep up with developments in the school" and "I give my time to help others with problems willingly". The items were aggregated and used as a single variable in our analysis $(\alpha=0.708)$. Finally, we controlled for the affiliation of the respondents - either MBA or graduate students and for gender. Prior research has shown that the amount of cooperation and help may occur differently in different groups (Farh et al., 2012).

\section{Results}

Descriptive statistics and correlations for all variables are shown in Table 1. EI shows significant correlations with $\mathrm{OCB}$, acquaintance and helping network in-degree centrality and helping network betweenness centrality.

Table 1: Means, Standard Deviations, and Zero-Order Correlations

\begin{tabular}{|c|c|c|c|c|c|c|c|c|c|}
\hline Variables & Mean & S.D. & 1 & 2 & 3 & 4 & 5 & 6 & 7 \\
\hline 1. affiliation & 0.54 & 0.50 & & & & & & & \\
\hline 2. gender & 0.27 & 0.45 & 0.06 & & & & & & \\
\hline 3. EI & 3.31 & 0.45 & -0.25 & -0.14 & & & & & \\
\hline $\begin{array}{l}\text { 4. acquaintance } \\
\text { network } \\
\text { in-degree } \\
\text { centrality } \\
\end{array}$ & 52.81 & 16.76 & $-0.60 * *$ & -0.23 & $0.38^{* * *}$ & & & & \\
\hline $\begin{array}{l}\text { 5. acquaintance } \\
\text { network } \\
\text { betweenness } \\
\text { centrality }\end{array}$ & 9.46 & 10.87 & $0.34 * *$ & -0.06 & 0.20 & 0.20 & & & \\
\hline
\end{tabular}




\begin{tabular}{|l|r|r|l|l|l|l|l|l|l|}
\hline $\begin{array}{l}\text { 6. helping } \\
\text { network } \\
\text { in-degree } \\
\text { centrality }\end{array}$ & 12.63 & 5.73 & $-0.63^{* *}$ & -0.16 & $0.34 * *$ & $0.90 * *$ & 0.04 & & \\
\hline $\begin{array}{c}\text { 7. helping } \\
\text { network } \\
\text { betweenness } \\
\text { centrality }\end{array}$ & 14.67 & 15.38 & 0.12 & -0.12 & $0.30 *$ & $0.38^{* *}$ & $0.49 * *$ & $0.40^{* *}$ & \\
\hline 8. OCB & 3.52 & 0.38 & -0.18 & $-0.27 *$ & $0.45^{* *}$ & $0.43^{* *}$ & $0.33^{* *}$ & $0.37 * *$ & $0.41^{* *}$ \\
\hline
\end{tabular}

$\mathrm{N}=63, * \mathrm{p}<0.05, * * \mathrm{p}<0.01$ (one-tailed test)

Table 2 shows the results of regression analysis on the effect of EI on social network centrality. EI is positively related to acquaintance network in-degree centrality ( $\beta=$ $0.23, \mathrm{p}<0.01)$, acquaintance network betweenness centrality $(\beta=0.30, \mathrm{p}<0.01)$, and helping network betweenness centrality $(\beta=0.34, \mathrm{p}<0.01)$, thus supporting hypotheses 1, 2 and 4 . The relationship between EI and helping network in-degree centrality is marginally significant $(\beta=0.18, p<0.10)$, thus rejecting hypothesis 3 .

Table 2: Results of Regression Analysis for EI Effect on Social Network

\begin{tabular}{|c|c|c|c|c|}
\hline & $\begin{array}{c}\text { acquaintance } \\
\text { network } \\
\text { in-degree } \\
\text { centrality }\end{array}$ & $\begin{array}{c}\text { acquaintance } \\
\text { network } \\
\text { betweenness } \\
\text { centrality }\end{array}$ & $\begin{array}{c}\text { helping } \\
\text { network } \\
\text { in-degree } \\
\text { centrality }\end{array}$ & $\begin{array}{c}\text { helping } \\
\text { network } \\
\text { betweenness } \\
\text { centrality }\end{array}$ \\
\hline affiliation & $-0.52(3.45)^{* *}$ & $0.41(2.69)^{* *}$ & $-0.57(1.19)^{* *}$ & $0.21(3.96)$ \\
\hline gender & $-0.17(3.82)$ & $-0.05(2.97)$ & $-0.10(1.32)$ & $-0.10(4.38)$ \\
\hline EI & $0.23(3.87)^{* *}$ & $0.30(3.02)^{* *}$ & $0.18(1.34) \dagger$ & $0.34(4.45)^{* *}$ \\
\hline $\mathbf{R}^{2}$ & 0.44 & 0.20 & 0.43 & 0.14 \\
\hline $\mathbf{F}$ & $15.06^{* *}$ & $4.75^{* *}$ & $14.54^{* *}$ & $3.08^{* *}$ \\
\hline
\end{tabular}

$\mathrm{N}=63, \dagger \mathrm{p}<.10,{ }^{*} \mathrm{p}<.05, * * \mathrm{p}<0.01$ (one-tailed test), Standard errors are in parentheses.

Table 3 shows the results of regression analysis on the effect of social network centrality on OCB. OCB is found to be positively influenced by acquaintance network in-degree centrality $(\beta=0.45, p<0.01)$, acquaintance network betweenness centrality $(\beta=0.42, p<0.01)$, helping network in-degree centrality $(\beta=0.38, p<0.01)$, and helping network betweenness centrality $(\beta=0.41, \mathrm{p}<0.01)$. Thus, hypotheses $5 \mathrm{a}, 5 \mathrm{~b}$, $6 \mathrm{a}$, and $6 \mathrm{~b}$ were supported. 
Table 3: Results of Regression Analysis for Social Network Effect on OCB

\begin{tabular}{|c|c|c|c|c|}
\hline & OCB & OCB & OCB & OCB \\
\hline affiliation & $0.10(0.11)$ & $-0.31(0.09)^{* *}$ & $0.07(0.11)$ & $-0.21(0.08) \dagger$ \\
\hline gender & $-0.17(0.10)$ & $-0.22(0.10) \dagger$ & $-0.21(0.10) \dagger$ & $-0.21(0.09) \dagger$ \\
\hline $\begin{array}{l}\text { acquaintance } \\
\text { network } \\
\text { in-degree } \\
\text { centrality }\end{array}$ & $0.45(0.00)^{* *}$ & & & \\
\hline $\begin{array}{l}\text { acquaintance } \\
\text { network } \\
\text { betweenness } \\
\text { centrality }\end{array}$ & & $0.42(0.00)^{* *}$ & & \\
\hline $\begin{array}{l}\text { helping network } \\
\text { in-degree } \\
\text { centrality }\end{array}$ & & & $0.38(0.01)^{* *}$ & \\
\hline $\begin{array}{l}\text { helping network } \\
\text { betweenness } \\
\text { centrality }\end{array}$ & & & & $0.41(0.10)^{* *}$ \\
\hline $\mathbf{R}^{2}$ & 0.22 & 0.26 & 0.19 & 0.26 \\
\hline $\mathbf{F}$ & $5.50 * *$ & $6.75 * *$ & $4.49 * *$ & $6.89 * *$ \\
\hline
\end{tabular}

$\mathrm{N}=63, \dagger \mathrm{p}<.10,{ }^{*} \mathrm{p}<.05,{ }^{* *} \mathrm{p}<0.01$ (one-tailed test), Standard errors are in parentheses.

Table 4 shows the mediation analysis results (Baron \& Kenny, 1986) of the effect of social network centrality. The Step 1 analysis showed that EI had a significant effect on OCB $(\beta=0.40, p<0.01)$. The second step showed significant effects of EI on social network centrality except for helping network in-degree centrality (see Table 2). The third step analysis indicated in the Step 2 of Table 4 that, all social network variables effectively mediated the relationship between EI and OCB. Thus, hypotheses $7 \mathrm{a}, 7 \mathrm{~b}$ and $7 \mathrm{~d}$ were supported. Since the link between EI and helping network in-degree centrality was insignificant, the mediation was not established and hypothesis $7 \mathrm{c}$ was not supported.

Table 4: Results of Regression Analysis for the Mediation Effects

\begin{tabular}{|l|c|c|c|c|c|}
\hline \multirow{2}{*}{ affiliation } & Step 1 & Step 2 & Step 2 & Step 2 & Step 2 \\
\cline { 2 - 6 } & $-0.04(0.09)$ & $0.12(0.11)$ & $-0.18(0.09)$ & $0.11(0.11)$ & $-0.11(0.09)$ \\
\hline gender & $-0.23(0.10) \dagger$ & $-0.17(0.10)$ & $-0.21(0.10) \dagger$ & $-0.20(0.10)$ & $-0.20(0.10)$ \\
\hline EI & $0.40(0.10)^{* *}$ & $0.33(0.10)^{* *}$ & $0.31(0.10)^{* *}$ & $0.35(0.10)^{* *}$ & $0.30(0.10)^{* *}$ \\
\hline $\begin{array}{l}\text { acquaintance } \\
\text { network } \\
\text { in-degree } \\
\text { centrality }\end{array}$ & & $0.32(0.00)^{* *}$ & & & \\
\hline
\end{tabular}




\begin{tabular}{|c|c|c|c|c|c|}
\hline $\begin{array}{l}\text { acquaintance } \\
\text { network } \\
\text { betweenness } \\
\text { centrality }\end{array}$ & & & $0.33(0.00) * *$ & & \\
\hline $\begin{array}{l}\text { helping } \\
\text { network } \\
\text { in-degree } \\
\text { centrality }\end{array}$ & & & & $0.28(0.01)^{* * *}$ & \\
\hline $\begin{array}{l}\text { helping } \\
\text { network } \\
\text { betweenness } \\
\text { centrality }\end{array}$ & & & & & $0.31(0.00)^{* *}$ \\
\hline $\mathbf{R}^{2}$ & 0.26 & 0.31 & 0.34 & 0.30 & 0.34 \\
\hline $\mathbf{F}$ & $6.50 * *$ & $0.35 * *$ & $7.24 * *$ & $5.97 * *$ & $7.12 * *$ \\
\hline$\Delta \mathbf{R}^{2}$ & & $0.06 * *$ & $0.09 * *$ & $0.04 \dagger$ & $0.08 * *$ \\
\hline
\end{tabular}

$\mathrm{N}=63, \dagger \mathrm{p}<.10, * \mathrm{p}<.05, * * \mathrm{p}<0.01$ (one-tailed test), Robust standard errors are in parentheses

In addition, the Sobel test was conducted to analyze the significance of the indirect effects (Sobel, 1982). As shown in Table 5, the highest significance is observed from the EI - acquaintance network in-degree centrality - OCB relationship (test statistics $=2.188, \mathrm{p}<0.05)$, followed by the EI - acquaintance network betweenness centrality - OCB (test statistics $=2.089, \mathrm{p}<0.05$ ), and the EI - helping network betweenness centrality - OCB (test statistics $=1.996, \mathrm{p}<0.05$ ).

Table 5: The Sobel Test of Indirect Effects with Social Network Position as Mediator

\begin{tabular}{|l|c|c|c|}
\hline \multicolumn{1}{|c|}{ Indirect effects } & Test statistics & Standard error & P-value \\
\hline $\begin{array}{l}\text { EI } \rightarrow \text { acquaintance network in- } \\
\text { degree centrality } \rightarrow \text { OCB }\end{array}$ & 2.188 & 0.051 & 0.029 \\
\hline $\begin{array}{l}\text { EI } \rightarrow \text { acquaintance network } \\
\text { betweenness centrality } \rightarrow \text { OCB }\end{array}$ & 2.089 & 0.043 & 0.037 \\
\hline $\begin{array}{l}\text { EI } \rightarrow \text { helping network in-degree } \\
\text { centrality } \rightarrow \text { OCB }\end{array}$ & 1.158 & 0.035 & 0.247 \\
\hline $\begin{array}{l}\text { EI } \rightarrow \text { helping network } \\
\text { betweenness centrality } \rightarrow \text { OCB }\end{array}$ & 1.996 & 0.054 & 0.046 \\
\hline
\end{tabular}

$\mathrm{N}=63$

According to the central limit theorem, an error term in the OLS follows an asymptotic normal distribution that allows us to take OLS estimation as unbiased when the sample size is more than 30 (Wooldridge, 2009). Once we assume that the coefficient estimations are unbiased, statistical power can be reliably accepted at the level of $\pi=0.8$ which represents $\alpha=0.05$ (Type I Error) and $\beta=0.2$ (Type II Error). This level of the statistical power has been normally accepted and recommended in the field (Moffatt, 2016). After executing a post-hoc statistical power analysis for multiple regression (Soper, 2020), we obtained $\pi>0.99$ for all the regression results we estimated. This power exceeds the level of what is normally accepted in the field. Based on the theoretical arguments and the post-hoc power analysis, we are certain that our OLS estimation are free from both Type I error and Type II error with our sample size. 


\section{Discussion}

This research contributes to the EI, social networks and OCB literatures in several ways. First, the higher the person's EI, the more active the person's social network was. Individuals with high EI showed more concentrated social interactions in acquaintance networks (in-degree centrality) and engaged in more intermediary social interactions (betweenness centrality). This finding indicates that EI is an important antecedent in fostering social interactions and gaining better positions in the social network. A key aspect of EI involves perspective taking ability with which one puts oneself in another's place for better evaluation of the situation (Hogan \& Hogan, 2002). Individuals with perspective taking ability tend to be active in social network because they provide sophisticated emotional support and have fewer egocentric biases (Galinsky \& Moskowitz, 2000). As an opposite case of EI, research on workplace incivility reports that instigators of incivility are often temperamental and emotionally irresponsible (Pearson et al., 2000). In contrast, high EI individuals, through their ability to perceive and manage emotions, tend to be at the centre of social interactions.

Second, high EI individuals received more assistance from various groups in the helping network. This finding indicates that high EI fosters getting help, not just from one's group, but also from other groups. As EI involves the ability to regulate and use one's emotions, individuals high in EI can be effective in providing verbal, nonverbal cues signalling that they need help (Lopes et al., 2006a). Because people are aware of potential negative consequences when they provide unneeded help or when their energy and resources get depleted by responding to help requests (Lanaj et al., 2016), they may be hesitant in providing help if signals are not strong enough. Besides effective indication of help needed, high EI individuals are adept at building highquality relationships. EI is important for initiating and maintaining social relationships, which, in turn, leads to help-giving and help-receiving interactions across diverse groups. Our hypothesis regarding a positive association between EI and helping network in-degree centrality was not supported. We suspect that the effect of one's affiliation $(\beta=-0.57, \mathrm{p}<0.01)$ had explained much of the variation in the model as most help-giving and help-receiving naturally occur within one's affiliated group. The impact of EI, on the other hand, was observed more strongly in helpgiving and help-receiving interactions across diverse groups, which necessitates active provision of cues indicating help needed.

Third, the more the individuals engage actively in social network, the more they engage in OCB. The higher the individuals score on centrality in acquaintance networks, the more likely they are to get involved in OCB. Through active social interactions, individuals become better aware of the needs of colleagues and the organization. Our finding is consistent with the ability-knowledge-motivation framework of citizenship behaviour (Dudley \& Cortina, 2008) which emphasizes accurate knowledge of others' needs and goals for OCB to be effective. The motivation aspect of citizenship behaviour is corroborated by our finding that, the more the individual receives assistance from others in the helping network, the more 
frequently they show OCB toward other people. In other words, individuals who received more help from others in the past (Time 1) exhibited more OCB in the present (Time 2). This finding demonstrates the effect of prior help receiving as a driver of motivation to later engage in OCB.

In sum, this study uncovered the effect of EI on social networks. Unlike prior studies that used the dyadic perspective, this study analysed a focal person's entire social network and revealed how EI affects an individual's position in the social network. While few studies have analysed through which process EI affects performance (Kim et al., 2009), the current study gives a new insight that EI has an important impact on $\mathrm{OCB}$, an unofficial but a critical factor in the effective functioning of organization.

Furthermore, this paper reveals that an individual's social relationships serve an important role as an antecedent of OCB. While social exchange perspective has been applied in understanding OCB, limited number of empirical studies have been conducted (Bowler \& Brass, 2006). This study applied social network analysis at two time points, and revealed how the experience of having received help in the past affected OCB in the future. Our findings suggest that the quality and the structure of social relationships should be considered importantly in studying OCB.

\section{Further Research Directions}

The current study is not without limitations, which suggest interesting avenues for future research. First, an implicit assumption in the study relates to the generalizability of our findings with MBA and graduate student sample to business organizations. In an effort to address this issue, we targeted our data collection at a large business school where most students had work experiences and/or prior knowledge in business administration. Also, gender composition of the sample roughly reflects that of the top 100 South Korean companies. Because demographic composition of groups or organizations tend to influence the way members interact with each other (Yang et al., 2019), we believe the effect of gender composition is to some extent reflected in the pattern of interactions revealed in our findings. Although our research setting was not business organizations, we expect that the observed relationships among EI, social network positions and OCB may hold in work settings as well. Prior research has revealed that one's level of EI (Vernon et al., 2008) and pattern of social interactions tend to be stable and predictable across different situations (i.e., behavioural signatures, Mischel, 2004). However, additional empirical research in business organizations is recommended to verify the current findings in work settings. 
A second limitation pertains to the modest sample size. In order to apply the twowave survey design, only the responses from those who participated in both Time 1 and 2 surveys were included in the analysis. However, the post-hoc power analysis result indicated that our multiple regression results were free from both Type I and II errors with the sample size. In addition, studies testing mediation have frequently used sample sizes between 51 and 100 (Fritz \& MacKinnon, 2007), which is typical of social network research as well (Kwok et al., 2018; Venkataramani et al., 2014). Nonetheless, we recommend future research to collect data from larger sample sizes.

Third, the study participants were drawn from MBA and graduate students in a large business school in South Korea, which reduces external validity. Although the East Asian context provides both theoretical and empirical implications, the pattern of social interactions and OCB may vary across different culture. Hence, more studies are warranted to verify the current findings in diverse settings with different cultural backgrounds.

Finally, our measurement of EI and OCB was based on the responses from a single source. To address concerns about potential common method bias, we used a twowave survey method (Podsakoff et al., 2012) and applied the social network analysis method to obtain a relatively objective measurement of in-degree and betweenness centrality in social networks. Future research may consider including more objective measurement of OCB such as peer or supervisor-rated OCB.

\section{Practical Implications for Asian Business}

The current research offers implications for practitioners in Asia. South Korea belongs to the East Asian cluster characterized as a collectivistic culture with an emphasis on achieving harmonious relationships with others (Markus \& Kitayama, 1991). In such cultural context, the ability of emotionally intelligent individuals to recognize and address others' or the group's needs and goals becomes essential for maintaining high quality relationships and effective functioning of organizations. Such ability to recognize and manage emotions and social relationships becomes even more critical given the recent organizational trends toward team-based structure (Bersin et al., 2016). In a team context where maintaining harmonious, collaborative relationships are important for effective coordination and functioning, ways to cultivate EI in employees and teams are of key interest for human resource management. One strategy may pertain to hiring job candidates with a high level of EI. Human resource department may administer written tests to job candidates in order to assess their level of EI (e.g., Self-Rated Emotional Intelligence Scale by Brackett et al., 2006). Also, managers may cultivate EI in employees by implementing on- or off-site training and development programs.

The need for EI training becomes even more paramount amidst the current unprecedented COVID-19 pandemic. Almost every kind of meetings and team tasks have undergone major transition toward non-face-to-face format (i.e., telecommuting or remote work, etc.). On-line interactions and communications have been found to be more difficult to transfer subtle meanings and emotions and more prone to 
miscommunication and misunderstanding (Belkin, 2009). In this circumstance, the ability to recognize and manage one's and others' emotions can be crucial for facilitating non-face-to-face interactions and keeping remote work on track. Hence, human resource department need to plan and invest in designing and implementing effective EI training programs.

In addition, the results suggest possible organizational strategies for creating a generalized norm for OCB. We found a direct positive relationship between receiving help and engaging in prosocial behaviours toward others in the organization. Such propensity appears stronger in East Asian culture of collectivistic thinking and interdependent selves (Markus \& Kitayama, 1991), thus extending dyadic helpreceiving to citizenship behaviours targeted at the members of the organization. In this regard, managers may find ways to facilitate help-giving and help-receiving practices and establish such practices as a generalized reciprocity norm. To establish systematic, institutionalized practices, for instance, organizations can set up an openinnovation system through which employees exchange ideas and advice. CEOs and top management teams may become a role model and actively communicate the importance of generalized reciprocity norm. In the East Asian Confucian context, in particular, those occupying central, high-status positions in social networks are expected to be more sensitive to others' needs and to fulfil their duties by addressing those needs (Lin et al., 2013). By actively engaging in help-receiving and help-giving interactions and OCB in social networks, leaders and managers at the centre of social networks can contribute to the establishment of generalized reciprocity norm in the organization.

Our study also gives an important insight on human resource practices such as performance appraisal and compensation system. Our study shows that help-receiving leads to help-giving, which finally increases generalized reciprocity. This generalized reciprocity is important to boost organizational social capital such as trust, trustworthiness and reciprocal fairness (Fehr \& Fischbacher, 2002). This result implies that one should help others first to make a virtual circle of generalized reciprocity. However, human resource management practices that are excessively competition-oriented (e.g., individual incentive system, etc.) have potential to decrease generalized reciprocity by restricting employees from helping others first. Decrease in generalized reciprocity inevitably reduces the level of social capital in the organization, which ultimately hamper organizational efficiency (Johnson \& Mislin, 2011). In order for employees to engage in active help-receiving and help-giving, human resource management practices need to nurture Asian collectivistic culture through team-based incentive system or profit sharing, for example, rather than emphasizing excessive competition among employees. 


\section{References}

Abraham, R., (2000), "The role of job control as a moderator of emotional dissonance and emotional intelligence-outcome relationships", Journal of Psychology, vol. 134, no. 2, pp.169-184.

Arieli, S., \& Sagiv, L., (2018), "Culture and problem-solving: Congruency between the cultural mindset of individualism versus collectivism and problem type", Journal of Experimental Psychology: General, vol. 147, pp. 789-814.

Baron, R. M., \& Kenny, D. A., (1986), "The moderator-mediator variable distinction in social psychological research: Conceptual, strategic, and statistical considerations", Journal of Personality and Social Psychology, vol. 51, pp. 1173-1182.

Belkin, L. Y., (2009), "Emotional contagion in the electronic communication context: Conceptualizing the dynamics and implications of electronic emotional encounters in organizations", Journal of Organizational Culture, Communications and Conflict, vol. 13, pp. 105-122.

Bersin, J., Geller, J., Wakefield, N., \& Walsh, B., (2016), Global human capital trends 2016, Deloitte University Press, New York.

Besley, T., \& Ghatak, M., (2018), "Prosocial motivation and incentives", Annual Review of Economics, vol. 10, pp. 411-438.

Böckler, A., Tusche, A., \& Singer, T., (2016), "The structure of human pro-sociality: Differentiating altruistically motivated, norm motivated, strategically motivated, and self-reported prosocial behaviour", Social Psychological and Personality Science, vol. 7, pp. 530-541.

Bowler, W. M., \& Brass, D. J., (2006), "Relational correlates of interpersonal citizenship behaviour: A social network perspective", Journal of Applied Psychology, vol. 91, pp. 70-82.

Borgatti, S. P., Everett, M. G., \& Freeman, L. C., (2002), UCINET 6 for windows: Software for social network analysis, Analytic Technologies, Massachusetts.

Brackett, M. A, Rivers, S. E., Shiffman, S., Lerner, N., \& Salovey, P., (2006), "Relating emotional abilities to social functioning: A comparison of self-report and performance measures of emotional intelligence", Journal of Personality and Social Psychology, vol. 91, no. 4, pp.780-795.

Carmeli, A., \& Josman, Z. E., (2006), "The relationship among emotional intelligence, task performance, and organizational citizenship behaviours", Human Performance, vol. 19, pp. 403-419.

Clarke, N., \& Mahadi, N., (2017), "The significance of mutual recognition respect in mediating the relationships between trait emotional intelligence, affective commitment and job satisfaction", Personality and Individual Differences, vol. 105, pp. 129-134.

Deckop, J. R., Cirka, C. C., \& Andersson, L. M., (2003), "Doing unto others: The reciprocity of helping behaviour in organizations", Journal of Business Ethics, vol. 47, pp. 101113.

Dovidio, J. F., Piliavin, J. A., Schroeder, D. A., \& Penner, L. A., (2017), The social psychology of prosocial behaviour, Psychology Press, New York.

Dudley, N. M., \& Cortina, J. M., (2008), "Knowledge and skills that facilitate the personal support dimension of citizenship", Journal of Applied Psychology, vol. 93, pp. 12491270.

Dutton, J. E., Roberts, L. M., \& Bednar, J., (2010), "Pathways for positive identity construction at work: Four types of positive identity and the building of social resources", Academy of Management Review, vol. 35, pp. 265-293.

Fang, R., Landis, B., Zhang, Z., Anderson, M. V., Shaw, J. D., \& Kilduff, M., (2015), "Integrating personality and social networks: A meta-analysis of personality, network position, and work outcomes in organizations", Organization Science, vol. 26, pp. 1243-1260. 
Farh, C. I., Seo, M. G., \& Tesluk, P. E., (2012), "Emotional intelligence, teamwork, effectiveness, and job performance: The moderating role of job context", Journal of Applied Psychology, vol. 97, pp. 890-900.

Fehr, E., \& Fischbacher, U., (2002), "Why social preferences matter: The impact of nonselfish motives on competition, cooperation and incentives", Economic Journal, vol. 112, pp. 1-33.

Fritz, M. S., \& MacKinnon, D. P., (2007), "Required sample size to detect the mediated effect", Psychological Science, vol. 18, pp. 233-239.

Galinsky, A. D., \& Moskowitz, G. B., (2000), "Perspective-taking: Decreasing stereotype expression, stereotype accessibility, and in-group favoritism", Journal of Personality and Social Psychology, vol. 78, pp. 708-724.

Grant, A. M., Dutton, J. E., \& Rosso, B., (2008), "Giving commitment: Employee support programs and the prosocial sensemaking process", Academy of Management Journal, vol. 51, pp. 898-918.

Hogan, J., \& Hogan, R., (2002), Leadership and sociopolitical intelligence, Erlbaum, New Jersey.

Johnson, N. D., \& Mislin, A. A., (2011), “Trust game: A meta-analysis", Journal of Economic Psychology, vol. 32, pp. 865-889.

Keltner, D., \& Haidt, J., (2001), Social functions of emotions, Guilford Press, New York.

Kwok, N., Hanig, S., Brown, D. J., \& Shen, W., (2018), "How leader role identity influences the process of leader emergence: A social network analysis", Leadership Quarterly, vol. 29, pp. 648-662.

Konovsky, M. A., \& Pugh, S. D., (1994), "Citizenship behaviour and social exchange", Academy of Management Journal, vol. 37, pp. 656-669.

Lanaj, K., Johnson, R. E., \& Wang, M., (2016), "When lending a hand depletes the will: The daily costs and benefits of helping", Journal of Applied Psychology, vol. 101, pp. 10971110.

Lin, I., Ho, Y., \& Lin, W. E., (2013), "Confucian and Taoist work values: An exploratory study of the Chinese transformational leadership behaviour", Journal of Business Ethics, vol. 113, pp. 91-103.

Lopes, P. N., Brackett, M. A., Nezlek, J. B., Schütz, A., Sellin, I., \& Salovey, P., (2004), "Emotional intelligence and social interaction", Personality and Social Psychology Bulletin, vol. 30, pp. 1018-1034.

Lopes, P. N., Salovey, P., Côté, S., \& Beers, M., (2005), "Emotion regulation ability and quality of social interaction", Emotion, vol. 5, pp. 113-118.

Lopes, P. N., Côté, S., \& Salovey, P., (2006a), An ability model of emotional intelligence: Implications for assessment and training, Lawrence Erlbaum, New Jersey.

Lopes, P. N., Grewal, D., Kadis, J., Gall, M., \& Salovey, P., (2006b), "Evidence that emotional intelligence is related to job performance and affect and attitudes at work", Psicothema, vol. 18, pp. 132-138.

MacCann, C., Jiang, Y., Brown, L. E., Double, K. S., Bucich, M., \& Minbashian, A., (2020), "Emotional intelligence predicts academic performance: A metaanalysis", Psychological Bulletin, vol. 146, pp. 150-186.

Markus, H. R., \& Kitayama, S., (1991), "Culture and the self: Implications for cognition, emotion, and motivation", Psychological Review, vol. 98, no. 2, pp. 224-253.

Mayer, J., \& Salovey, P., (1997), What is emotional intelligence?, Basicbooks, New York.

Miao, C., Humphrey, R. H., \& Qian, S., (2017), "Are the emotionally intelligent good citizens or counterproductive? A meta-analysis of emotional intelligence and its relationships with organizational citizenship behaviour and counterproductive work behaviour", Personality and Individual Differences, vol. 116, pp. 144-156.

Mischel, W., (2004), "Toward an integrative science of the person", Annual Review of Psychology, vol. 55, pp. 74-97.

Mo, S., \& Shi, J., (2017), "Linking ethical leadership to employees' organizational citizenship behaviour: Testing the multilevel mediation role of organizational concern", Journal of Business Ethics, vol. 141, pp. 151-162. 
Moffatt, P. G., (2016), Experimetrics: Econometrics for experimental economics, Palgrave Macmilan, New York.

Nowak, M. A., \& Roch, S., (2007), "Upstream reciprocity and the evolution of gratitude", Proceedings of the royal society B: Biological Sciences, vol. 274, no. 1610, pp. 605-610.

Oh, H., \& Kilduff, M., (2008), "The ripple effect of personality on social structure: Selfmonitoring origins of network brokerage", Journal of. Applied Psychology, vol. 93, pp. $1155-1164$.

O'Neill, T. A., McLarnon, M. J., Xiu, L., \& Law, S. J., (2016), "Core self-evaluations, perceptions of group potency, and job performance: The moderating role of individualism and collectivism cultural profiles", Journal of Occupational and Organizational Psychology, vol. 89, pp. 447-473.

Organ, D. W., (1988), Organizational citizenship behaviour: The good soldier syndrome. Lexington Books, Lexington.

Pearson, C. M., Andersson, L. M., \& Porath, C. L., (2000), "Assessing and attacking workplace incivility", Organizational Dynamics, vol. 29, pp. 123-137.

Piliavin, J. A., \& Charng, H. W., (1990), "Altruism: A review of recent theory and research", Annual Review of Sociology, vol. 16, pp. 27-65.

Podsakoff, P. M., Ahearne, M., \& MacKenzie, S. B., (1997), "Organizational citizenship behaviour and the quantity and quality of work group performance", Journal of Applied Psychology, vol. 82, pp. 262-270.

Podsakoff, P., MacKenzie, S., \& Podsakoff, N., (2012), "Sources of method bias in social science research and recommendations on how to control it", Annual Review of Psychology, vol. 63, pp. 539-569.

Rubenstein, A. L., Allen, D. G., \& Bosco, F. A., (2019), "What's past (and present) is prologue: Interactions between justice levels and trajectories predicting behavioural reciprocity", Journal of Management, vol. 45, pp. 1569-1594.

Salovey, P., \& Mayer, J. D., (1990), "Emotional intelligence", Imagination, Cognition and Personality, vol. 9, no. 3, pp.185-211.

Scott, J., (2000), Social network analysis: A handbook, Sage Publication, London.

Schutte, N. S., Malouff, J. M., Bobik, C., Coston, T. D., Greeson, C., Jedlicka, C., Rhodes, E., \& Wendorf, G., (2001), "Emotional intelligence and interpersonal relations", Journal of Social Psychology, vol. 141, no. 4, pp. 523-536.

Simpson, B., \& Willer, B., (2015), "Beyond altruism: Sociological foundations of cooperation and prosocial behaviour", Annual Review of Sociology, vol. 41, pp. 43-63.

Sobel, M. E., (1982), Asymptotic confidence intervals for indirect effects in structural equation models, American Sociological Association, Washington.

Soper, D. S., (2020), Post-hoc statistical power calculator for multiple regression, Retrieved from: http://www.danielsoper.com/statcalc.

The Outsourcing Times, (2019), "Average gender ratio of employees 81 to 19 among top conglomerate groups" Retrieved from: https://www.outsourcing.co.kr/news/articleVi ew.html?idxno=84461

Thielmann, I., Spadaro, G., \& Balliet, D., (2020), "Personality and prosocial behaviour: A theoretical framework and meta-analysis", Psychological Bulletin, vol. 146, pp. 30-90.

Triandis, H. C., (1995), Individualism and collectivism, Westview, Colorado.

Venkataramani, V., Richter, A. W., \& Clarke, R., (2014), "Creative benefits from wellconnected leaders: Leader social network ties as facilitators of employee radical creativity", Journal of Applied Psychology, vol. 99, pp. 966-975.

Vernon, P. A., Petrides, K. V., Bratko, D., \& Schermer, J. A., (2008), “A behavioural genetic study of trait emotional intelligence", Emotion, vol. 8, pp. 635-642.

Vignoles, V. L., Owe, E., Becker, M., Smith, P. B., Easterbrook, M. J., Brown, R., \& Lay, S., (2016), "Beyond the 'east-west' dichotomy: Global variation in cultural models of selfhood”, Journal of Experimental Psychology: General, vol. 145, pp. 966-1000. 
Wong, C. S., \& Law, K. S., (2002), "The effects of leader and follower emotional intelligence on performance and attitude: An exploratory study", The Leadership Quarterly, vol. 13, no. 3, pp. 243-274.

Wooldridge, J. M., (2009), Introductory econometrics: A modern approach, South-Western Cengage Learning, Ohio.

Yang, Y., Chawla, N. V., \& Uzzi, B., (2019), "A network's gender composition and communication pattern predict women's leadership success", Proceedings of the National Academy of Sciences, vol. 116, pp. 2033-2038.

Yoshikawa, K., Wu, C. H., \& Lee, H. J., (2018), "Generalized social exchange and its relevance to new era workplace relationships", Industrial and Organizational Psychology, vol. 11, pp. 486-492.

Yusof, M. M., Ho, J. A., Imm, S. N. S., \& Zawawi, D., (2019), "Weeding out deviant workplace behaviour in downsized organizations: The role of emotional intelligence and job embeddedness", Asian Journal of Business Research, vol. 9, no. 3, pp.115-144.

Zagenczyk, T. J., \& Powell, E. E., (2019), "Social networks as structural and relational antecedents of identification and citizenship", Academy of Management Proceedings, vol. 2019, p. 11706. 